\title{
Identification of an Alkylhydroquinone from Rhus succedanea as an Inhibitor of Tyrosinase and Melanogenesis
}

\author{
Yun-Ru Chen, ${ }^{\dagger}$ Robin Y.-Y. Chiou, ${ }^{\S}$ Ting-Yu Lin, ${ }^{\dagger}$ Cheng-Po Huang, ${ }^{\dagger}$ \\ Wei-Chien Tang, ${ }^{\dagger}$ Shui-Tein Chen, ${ }^{*}$ AND Shwu-Bin Lin ${ }^{*},+\perp, \nabla$
}

\begin{abstract}
Department of Clinical Laboratory Sciences and Medical Biotechnology, National Taiwan University, Taipei, Taiwan, Republic of China; Department of Food Science, National Chiayi University, Chiayi, Taiwan, Republic of China; Institute of Biological Chemistry and Genomic Research Center, Academia Sinica, Taipei, Taiwan, Republic of China; Department of Laboratory Medicine, National Taiwan University Hospital, Taipei, Taiwan, Republic of China; and Institute of Applied Mechanics, National Taiwan University, Taipei, Taiwan, Republic of China
\end{abstract}

\begin{abstract}
The alkylhydroquinone $10^{\prime}(Z)$-heptadecenylhydroquinone [HQ17(1)], isolated from the sap of the lacquer tree Rhus succedanea, was found to inhibit the activity of tyrosinase and to suppress melanin production in animal cells. The $\mathrm{IC}_{50}$ of HQ17(1) as a tyrosinase inhibitor was $37 \mu \mathrm{M}$ versus $70 \mu \mathrm{M}$ for hydroquinone $(\mathrm{HQ})$, a known inhibitor of tyrosinase and melanogenesis. For the inhibition of melanin production in mouse B16 melanoma cells, the $\mathrm{EC}_{50}$ of $\mathrm{HQ17}(1)$ was $40 \mu \mathrm{M}$ versus $124 \mu \mathrm{M}$ for $\mathrm{HQ}$. HQ17(1) induced much less oxidative stress than did HQ. The effectiveness in inhibiting melanin production could be mimicked by intermittent exposure of cells to HQ17(1). The potent inhibitory effects of HQ17(1) on tyrosinase activity and melanin production are likely due to its heptadecenyl chain, which facilitates retention of the compound in cell membrane compartments and may impede oxidation of the hydroquinone ring. As tyrosinase activity accounts for postharvest browning of botanical products and animal skin melanogenesis, HQ17(1) could be useful for the preservation of these products or as a skin-whitening cosmetic.
\end{abstract}

KEYWORDS: Tyrosinase inhibitor; Rhus succedanea; alkylhydroquinone; antimelanogenesis

\section{INTRODUCTION}

The tyrosinases (EC 1.14.18.1) are a class of oxidoreductases. Proteins with tyrosinase activity have been isolated from a wide variety of organisms including plants, fungi, bacteria, insects, amphibians, and mammals. Tyrosinases from different species are diverse in their primary protein structure, tissue distribution, and cellular location. All tyrosinases have in common a coppercontaining catalytic center $(1,2)$. Also known as polyphenol oxidase, tyrosinase in plants catalyzes the postharvest oxidation of polyphenolic compounds. This consequently leads to brownish oxidation products that often reduce the market value of botanical and fishery products $(3,4)$. In mammalian skin, tyrosinase exists as a type I transmembrane protein that catalyzes

* Address correspondence to this author at Rm. 522, Diagnostic Building, National Taiwan University, Chang-Te St., Taipei 100, Taiwan, ROC (e-mail sblin@ntu.edu.tw; telephone +886-2-28735137; fax $+886-2-23711574)$.

${ }^{\dagger}$ Department of Clinical Laboratory Sciences and Medical Biotechnology, National Taiwan University.

${ }^{\S}$ National Chiayi University.

\# Academia Sinica.

${ }^{\perp}$ National Taiwan University Hospital.

${ }^{\nabla}$ Institute of Applied Mechanics, National Taiwan University. melanogenesis in epidermal layers. The enzyme oxidizes tyrosine to dihydroxy-L-phenylalanine (L-DOPA) and subsequently to dopachrome, which further polymerizes to melanin $(5,6)$. Although melanin absorbs and scatters UV light, reducing the harmful effects of sunlight on skin, overproduction of melanin sometimes brings about an undesired skin tone. Therefore, the development of high-quality tyrosinase inhibitors that can be used as preservatives for fresh food or as skinwhitening agents has been pursued. The search for a plant source of tyrosinase inhibitors is a focus of phytochemical research because plants constitute a rich source of bioactive chemicals, and it has been reported that most of these compounds possess few harmful adverse effects $(7,8)$.

Hydroquinone (HQ) is a well-known tyrosinase inhibitor and antimelanogenesis compound that has been used as an active ingredient in cosmetics and pharmaceuticals since the 1960s. However, HQ was found to irritate skin and, after long-term use, it may cause permanent leucoderma, scarring, or ochronosis. The use of HQ in cosmetics has been banned by the European Committee, and now its use is limited in formulations prescribed by physicians and dermatologists (9). In addition to the detrimental effect on skin, the safety of HQ has been further questioned because both in vitro cell studies and animal 
experiments indicate that the compound could be mutagenic and tumorigenic. These harmful effects may be due to the fact that $\mathrm{HQ}$ is readily oxidized by cellular enzymes. Its oxidation products, quinones and reactive oxygen species (ROS), cause oxidative damage to cellular proteins, DNA, and membranes (9-11). HQ and HQ-glycoside are contained in our diet. Wheat, rice, pears, onions, and berries or drinks such as coffee and tea are rich in HQ (9). Hydroquinone- $O$ - $\beta$-D-glucopyranoside (arbutin) from the California buckeye has been characterized as a tyrosinase inhibitor. Another HQ derivative, gentisic acid (2,5-dihydroxybenzoic acid), from gentian roots has also been found to be a tyrosinase inhibitor. These two HQ derivatives have been indicated to act as prodrugs; that is, the compounds exert their effect via the release of HQ after being taken up by cells (12). Arbutin is currently a common whitening ingredient in cosmetics, although the compound has been reported to interfere with the uptake of tyrosine, thus negatively affecting cell growth (13). In addition to inhibiting tyrosinase, it has been implicated in the inhibition of 5,6-dihydroxyindole-2-carboxylic acid polymerase, another enzyme involved in the catalysis of melanin polymerization (13). On the other hand, gentisic acid and its alkyl ester derivatives, in addition to acting via release of HQ, may inhibit tyrosinase through binding to a copper ion in the active site of the enzyme (14). In terms of safety, it has been suggested that both gentisic acid and the alkyl gentisate may be less mutagenic than HQ, although further experimental proof is needed (14).

We previously isolated three hydroquinone derivatives from the sap of the lacquer tree Rhus succedanea L. (15). Lacquer trees belonging to the sumac family (Anacardiaceae) are cultivated for their sap, which has been used as a coating material for lacquer wares for thousands of years in Asia. The latex-like sap dries and polymerizes into a tough and brilliant film. The forming of this polymeric film involves complicated enzymatic oxidative coupling of a variety of biomolecules $(16,17)$. In addition to this application, Rhus has long been a folk medicine in Asia, and the medicinal uses have been recorded in the ancient traditional Chinese medicinal (TCM) document "Bern Chao Gan Mo". At least seven TCM preparations derived from the fruit, leaf, root, or bark of the Rhus trees have been documented (18). The heptadecahydroquinone compounds isolated from Rhus sap (15), 10'(Z)-heptadecenylhydroquinone [HQ17(1)], 10'(Z),13'(E)-heptadecadienylhydroquinone [HQ$17(2)]$, and $10^{\prime}(Z), 13^{\prime}(E), 15^{\prime}(E)$-heptadecatrienylhydroquinone [HQ17(3)] differ in certain biochemical properties and in their cytotoxicity to various cell lines (19). HQ17(1) (Figure 1A) was also isolated from Tapirira guianensis (20) and has been characterized as a cytotoxic compound in several cancer cell lines $(15,20)$. However, in this study, this compound was shown to exhibit relatively low cytotoxicity on skin cells and can inhibit the activity of tyrosinase and melanogenesis. The inhibition kinetics of HQ17(1) on tyrosinase was characterized. Furthermore, HQ17(1) was compared with HQ in both efficacy and safety. Cellular distribution of HQ17(1) was studied and the contribution of the hydrophobic heptadecenyl chain was discussed.

\section{MATERIALS AND METHODS}

Materials. Tyrosinase (from Agaricus bisporus), L-DOPA, hydroquinone, Dulbecco's Modified Eagle's Medium (DMEM), L-glutamine, $\alpha$-melanin stimulation hormone $(\alpha-\mathrm{MSH}), 4$-nitrophenyl phosphate disodium salt hexahydrate ( $p$ NPP), and HPLC-grade water were purchased from Sigma Chemical Co. (St. Louis, MO). Antibiotics, trypsin/EDTA, and nonessential amino acids were purchased from Biological Industries (Kibbutz Beit Haemek, Israel). Phosphate-buffered saline (PBS) was purchased from Amresco, Inc. (Solon, MO). 2', $7^{\prime}$ -
(A)<smiles>[R]c1cccc(O)c1</smiles>

HQ: $\quad \mathrm{R}=\mathrm{H}$

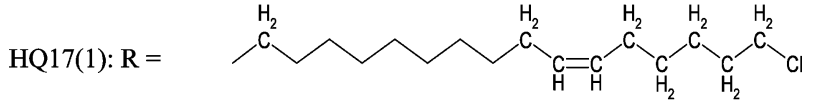

(B)

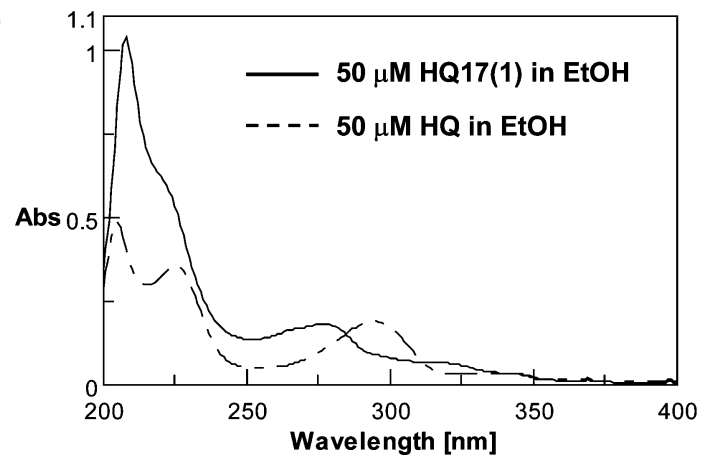

Figure 1. (A) Chemical structures and (B) UV absorption profile of $10^{\prime}(Z)$ heptadecenylhydroquinone [HQ17(1)] and hydroquinone (HQ).

Dichlorodihydrofluorescin diacetate (DCFDA) was purchased from Molecular Probes (Eugene, OR). HPLC-grade methanol was purchased from Mallinckrodt Baker Inc. (Philipsburg, NJ). Absolute ethanol (Riedel-de Haën ethanol absolute SPECTRANAL) was purchased from Sigma-Aldrich Laborchemikalien GmbH (Seelze, Germany). Opti-MEM and horse serum were purchased from Invitrogen Co. (Carlsbad, CA). Fetal bovine serum (FBS) was obtained from Gibco (Grand Island, NY). An Analytical HPLC C18 column $(250 \times 4.6 \mathrm{~mm}$, Polaris 5 C18A) and a preparative C-18 column $(250 \times 10 \mathrm{~mm}$, DiscoveryBIO wide pure C18) were purchased from Varian Inc. (Walnut Creek, CA) and Supelco Inc. (St. Louis, MO), respectively.

Purification of HQ17(1) from Rhus Sap. Rhus sap was harvested from lacquer trees planted in the mountainous area of central Taiwan. The purification protocol was modified from that described previously (15). Briefly, an aliquot of the sap (100 g) was mixed thoroughly with EtOH $(80 \%, 900 \mathrm{~mL})$. The mixture was centrifuged at $5000 \mathrm{~g}$ for 5 min. The upper layer was mixed with an equal volume of $\mathrm{MeOH}(20 \%)$. The supernatant was subsequently extracted with a 3-fold volume of ethyl acetate and centrifuged at $700 \mathrm{~g}$ for $20 \mathrm{~min}$. The ethyl acetate layer was collected and vaccuum-dried. The residue was redissolved in $100 \% \mathrm{EtOH}$ and subjected to HPLC (Chrom Tech, Inc., Apple Valley, $\mathrm{MN}$ ) on a preparative $\mathrm{C}-18$ column, isocratic elution using $90 \%$ $\mathrm{MeOH}(5 \mathrm{~mL} / \mathrm{min})$, and a detector monitoring at $A_{280 \mathrm{~nm}}$. The purified HQ17(1) was dissolved in EtOH, and the UV absorption spectrum was measured using a SpectraMax M5 Microplate Reader with Triple-mode cuvette port (Molecular Devices, Sunnyvale, CA). The purity was also checked by HPLC using an analytical C18 column, isocratic elution by $90 \% \mathrm{MeOH}(1 \mathrm{~mL} / \mathrm{min})$, and a photodiode array detector (DAD 230, Chrom Tech, Inc.).

Cell Culture. Mouse melanoma B16 and human melanoma A2058 cells were cultured in DMEM supplemented with 10\% FBS. Mouse primary melanocytes were cultured in Opti-MEM containing 10\% horse serum. Both DMEM and Opti-MEM contained $100 \mathrm{U} / \mathrm{mL}$ penicillin, $0.1 \mathrm{mg} / \mathrm{mL}$ streptomycin, $1 \%$ nonessential amino acids, and $2 \mathrm{mM}$ L-glutamine. All cells were cultured in a humidified atmosphere containing $\mathrm{CO}_{2}(5 \%)$ at $37{ }^{\circ} \mathrm{C}$ and were propagated by brief treatment with trypsin and then resuspended in the culture medium.

Cell Viability Assay. Cell viability was evaluated by measuring cellular acid phosphatase (ACP) activity. Briefly, $5 \times 10^{4}$ cells in 1 $\mathrm{mL}$ of medium were cultured in 24-well plates and treated with various concentrations of compounds for $72 \mathrm{~h}$. After that, the cells were washed twice with PBS and then $p$ NPP solution $(100 \mu \mathrm{L}$ at $10 \mathrm{mM})$ containing 
$0.1 \%$ Triton $\mathrm{X}-100$ in $0.1 \mathrm{M}$ sodium acetate was added to each well. After incubation at $37{ }^{\circ} \mathrm{C}$ for $30-40 \mathrm{~min}$, the reaction was stopped by the addition of $\mathrm{NaOH}(10 \mu \mathrm{L}$ at $1 \mathrm{~N})$, and the absorbance at $410 \mathrm{~nm}$ was measured using a SpectraMax M5 microplate reader (Molecular Devices). The median effective concentration $\left(\mathrm{EC}_{50}\right)$ was determined as described previously (21).

Assay for Tyrosinase Activity. A total volume of $180 \mu \mathrm{L}$ of assay mixture containing $1 \mathrm{mM}$ L-DOPA, $50 \mathrm{mM}$ phosphate buffer (pH 6.8), and different concentrations of test compounds was added to each well of a 96 -well plate and then incubated at $25^{\circ} \mathrm{C}$ for $10 \mathrm{~min}$. After that, $20 \mu \mathrm{L}$ of aqueous tyrosinase solution $(1000 \mathrm{U} / \mathrm{mL})$ was added. Dopachrome production was determined by absorbance at $492 \mathrm{~nm}$ in a microplate reader for $10 \mathrm{~min}(22)$.

Assay for Melanogenesis. The amount of melanin present in the cell culture medium was used as an index for melanogenesis. Culture medium without phenol red was used to cultivate B16 cells, A2058 cells, and primary melanocytes. The cells $\left(5 \times 10^{4}\right.$ cells in $1 \mathrm{~mL}$ of medium) were cultured in a 24-well plate and treated with $\alpha$-MSH $(0.1 \mu \mathrm{M})$ for $4 \mathrm{~h}$. Various concentrations of HQ17(1) or HQ were then added, and then the cells were cultivated for a further $72 \mathrm{~h}$. To study the influence of intermittent drug exposure, B16 cells were exposed to HQ17(1) or HQ for 1-8 h. After the exposure, the cells were washed with PBS and further cultured in fresh medium for a total of $72 \mathrm{~h}$, including the drug exposure time. At the end, aliquots of culture medium $(200 \mu \mathrm{L})$ were transferred to a 96-well plate, and the amount of melanin was evaluated by absorbance at $400 \mathrm{~nm}$. The melanin level was normalized to cell viability (22).

Measurement of HQ17(1) in Cell Membrane and Cytosol Fractions. HQ17(1) was recovered from membrane and cytosol fractions of the treated cells and quantified by HPLC. B16 cells $(2.5 \times$ $10^{6}$ cells in $6 \mathrm{~mL}$ of medium) were cultured in the presence of $40 \mu \mathrm{M}$ HQ17(1). After cultivation for 4, 8, 12, 24, 48, or $72 \mathrm{~h}$, cell membrane and cytosol fractions were prepared with procedures modified from a previous paper (23). Briefly, the cells were collected by trypsinization, washed twice with PBS, suspended in $200 \mu \mathrm{L}$ of cell lysis buffer and disrupted by sonication (10 s, twice). The cell lysates were centrifuged at $13200 \mathrm{~g}$ at $4{ }^{\circ} \mathrm{C}$ for $15 \mathrm{~min}$ to separate the membrane fraction (residues) from the cytosol fraction (supernatant). To both fractions was added $34.4 \mu \mathrm{g}$ of HQ17(2) as an internal standard (IS) for quantification of HQ17(1) by HPLC. To extract HQ17(1) and the IS, both fractions were dispersed in absolute EtOH with sonication (10 s) and centrifuged at $5000 \mathrm{~g}$ for $10 \mathrm{~min}$, and then the supernatants were collected. The extraction was repeated three times, and the volume of EtOH for each time was $1,0.5$, and $0.3 \mathrm{~mL}$, respectively. Finally, the three extracts were combined, vaccuum-dried, and resuspended in 35 $\mu \mathrm{L}$ of EtOH and subjected to analytical HPLC; $10 \mu \mathrm{L}$ was injected for each chromatography. The quantities $(\mu \mathrm{g})$ of the recovered HQ17(1) in the membrane fraction and the cytosol fraction were calculated on the basis of the peak ratio of HQ17(1) (retention time = 21.1 $\mathrm{min}$ ) to the IS (retention time $=16.5 \mathrm{~min}$ ) in the chromatogram.

Cellular ROS Levels. Melanoma B16 cells $\left(5 \times 10^{6}\right.$ cells in $3 \mathrm{~mL}$ of medium) were cultured in 6-well plates and treated with various concentrations of HQ17(1) or HQ for $8 \mathrm{~h}$. DCFDA was then added to the wells, and the cells were cultured for another $30 \mathrm{~min}$. After that, the cells were washed with PBS, trypsinized, and then analyzed by a flow cytometer (Epics XL-MCL, Beckman Coulter, Inc.). The data were analyzed with EXPO 32 software (Beckman Coulter, Inc.). Cells with increased ROS content appeared as a population with a higher fluorescence intensity (24).

Statistical Analysis. The significance of the drug effect was analyzed using a Student's $t$ test. An asterisk (*) indicates $p<0.05$.

\section{RESULTS AND DISCUSSION}

Purification and Characterization of HQ17(1). In the preparative HPLC condition, three hydroquinone derivatives, HQ17(3), HQ17(2), and HQ17(1), were consecutively obtained. The retention times were $10.7,12.1$, and $16.0 \mathrm{~min}$, respectively. HQ17(1) is the most hydrophobic molecule among the three compounds. Using the purification protocol described above, the yield of HQ17(1) was about $23 \mathrm{mg} / \mathrm{g}$ of sap. The purified
(A)

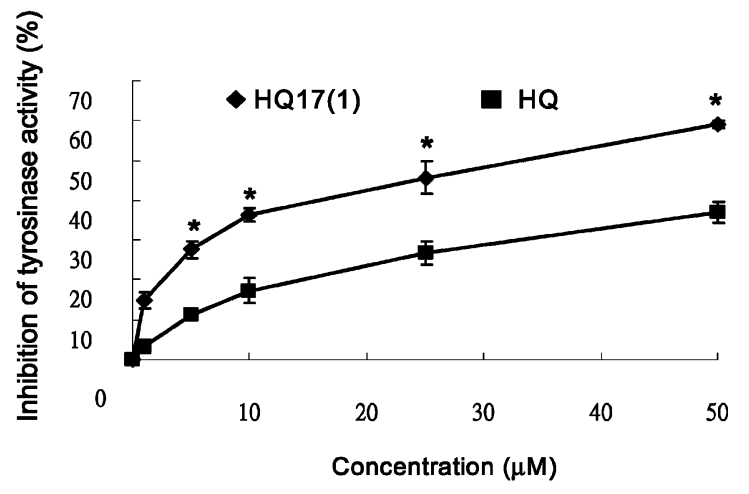

(B) Lineweaver-Burk plot

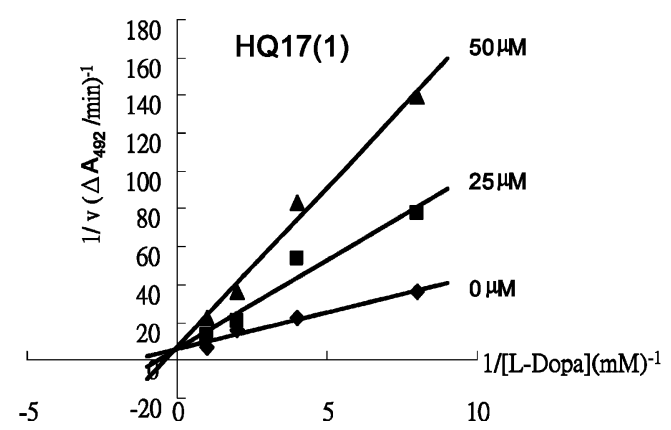

Figure 2. Inhibition of mushroom tyrosinase by HQ17(1): (A) dosedependent inhibition of tyrosinase activity by $\mathrm{HQ}$ and $\mathrm{HQ17}(1)$ [the asterisk $\left(^{*}\right)$ indicates $\left.p<0.05\right]$; (B) Lineweaver-Burk plot of HQ17(1). The reactions of L-DOPA (substrate) at concentrations of $1,0.5,0.25$, and $0.125 \mathrm{mM}$ were performed in the presence of 0,25 , or $50 \mu \mathrm{M} \mathrm{HQ17(1).}$ The initial velocity $(v)$ of each reaction was measured, and then the reciprocals of velocity and substrate concentration were plotted.

HQ17(1) was identified by mass spectroscopy and NMR spectroscopy as described previously (15). Analytical HPLC equipped with a photodiode array detector (200-600 nm) and UV absorption spectroscopy were routinely used to monitor the identity and purity of the compound. In the analytical HPLC, the retention time for HQ17(1) was $21.1 \mathrm{~min}$. The UV absorption spectrum of HQ17(1) showed a profile to some extent similar to HQ but with shifted absorption peaks (Figure 1B).

Identification of HQ17(1) as a Tyrosinase Inhibitor. The capability of HQ17(1) to inhibit tyrosinase activity was studied using L-DOPA as a substrate. The inhibitions of tyrosinase activity by HQ17(1) and by HQ were compared and are shown in Figure $2 \mathrm{~A}$. In the concentration range of $0-50 \mu \mathrm{M}$, the inhibition was dose-dependent for both inhibitors, and HQ17(1) inhibited tyrosinase more efficiently than $\mathrm{HQ}$. The $\mathrm{IC}_{50}$ of HQ17(1) was $37 \mu \mathrm{M}$, whereas that of HQ was extrapolated to be $70 \mu \mathrm{M}$. The inhibition kinetics of tyrosinase-catalyzed L-DOPA oxidation by HQ17(1) was further characterized. As shown in the Lineweaver-Burk plot in Figure 2B and in the summarized kinetic parameters shown in Table 1, HQ17(1) exerted a mixed-type inhibition on tyrosinase. The kinetics showed statistically significant increases in $K_{\mathrm{M}}(p<0.05)$ and less significant decreases in $V_{\max }(0.05<p<0.1)$. In a mixedtype inhibition, the substrate may bind to the enzyme active site or the substrate-enzyme complex. We found that HQ17(1) was oxidized by tyrosinase at a very slow rate (data not shown), suggesting it binds to the enzyme active site. The affinity of HQ17(1) binding to tyrosinase is much stronger than that of L-DOPA as revealed by the $K_{\mathrm{I}}$ and $K_{\mathrm{M}}$ values; the former is $10^{3}$ lower than the latter. Whether HQ17(1) binds to the 
Table 1. Kinetic Parameters of Tyrosinase As Affected by HQ17(1) ${ }^{a}$

\begin{tabular}{lcclc}
\hline inhibitor & dose $(\mu \mathrm{M})$ & $k_{\mathrm{M}}(\mathrm{mM})$ & $V_{\max }\left(\Delta A_{492} / \mathrm{min}\right)$ & $K_{\mathrm{i}}(\mu \mathrm{M})$ \\
\hline none & & $0.70 \pm 0.07$ & $0.178 \pm 0.029$ & \\
HQ17(1) & 25 & $1.54 \pm 0.11^{*}$ & $0.164 \pm 0.012^{b}$ & $1.52 \pm 0.09$ \\
& 50 & $2.42 \pm 0.15^{*}$ & $0.143 \pm 0.024^{b}$ & $1.81 \pm 0.12$
\end{tabular}

${ }^{a}$ The kinetic parameters $K_{\mathrm{M}}$ and $V_{\max }$ were obtained with L-DOPA as a substrate using the Lineweaver-Burk plot shown in Figure 2B. ${ }^{b}$ Statistical analysis indicates $p=0.06$ and 0.08 for 25 and $50 \mu \mathrm{M}$, respectively. The asterisk $\left(^{*}\right)$ indicates $p<$ 0.05 .

substrate-enzyme complex remains to be studied. When these data are combined, it is evident that HQ17(1) is a potent tyrosinase inhibitor.

Inhibition of Melanin Production by HQ17(1) in Mammalian Cell Lines. The ability of HQ17(1) to inhibit melanin production was evaluated using a cell-based assay. As shown in Figure 3, HQ17(1) effectively inhibited melanin production in the melanoma cell lines as well as in normal cells (primary murine melanocytes). After a $72 \mathrm{~h}$ treatment, the $\mathrm{EC}_{50}$ values of HQ17(1) for inhibition of melanin production in B16 cells, A2058 cells, and normal melanocytes were 40, 49, and $36 \mu \mathrm{M}$, respectively. The greater observed inhibition of melanin production in normal melanocytes may be due to their higher melanin production rate than the other two cell types. HQ exerted less inhibitory effects than did HQ17(1) on melanin production in these cell lines. The $\mathrm{EC}_{50}$ values of $\mathrm{HQ}$ for inhibition of melanin production in B16 cells and A2058 cells were extrapolated to be 124 and $109 \mu \mathrm{M}$, respectively. It is clear that HQ17(1) is a more potent melanogenesis inhibitor than is HQ. As for cytotoxicity, the cell viabilities were $80 \%$ in B16 cells, $87 \%$ in A2058 cells, and $89 \%$ in melanocytes at the $\mathrm{EC}_{50}$ of HQ17(1) for melanin production inhibition. Thus, HQ17(1) inhibited melanin synthesis more efficiently than HQ and exerted low cytotoxicity.

Eight Hour Intermittent Treatment and 72 h Continuous Treatment of HQ17(1) Caused the Same Level of Inhibition in Cellular Melanin Production. As shown in Figure 4A, timedependent inhibition of melanin production was observed when B16 cells were intermittently treated with HQ17(1) for 1, 2, 4, or $8 \mathrm{~h}$. The level of melanin production inhibition caused by an $8 \mathrm{~h}$ intermittent treatment was about the same at $72 \mathrm{~h}$ of continuous treatment. In contrast, intermittent treatment with HQ did not cause obvious melanin production inhibition. HPLC chromatograms of the membrane fraction extractions showed two major peaks, the IS (retention time $=16.5 \mathrm{~min}$ ) and HQ17(1) (retention time $=21.1 \mathrm{~min}$ ) (Figure 4B). As the HPLC was monitored by a photodiode array detector, the identity of each peak was confirmed by the UV absorption spectra. The HPLC chromatograms of the cytosol fraction showed many peaks in addition to the IS and HQ17(1) (Supporting Information Figure 1). Some of the additional peaks could be cellular molecules, and the others might be metabolites of HQ17(1); further analysis by LC-MS is needed to prove this presumption. The quantities of the recovered HQ17(1) in the membrane fraction [m-HQ17(1)] and the cytosol fraction [c-HQ17(1)] were calculated. As shown in the inset of Figure 4B, the m-HQ17(1) and c-HQ17(1) were 28.0-38.7 and 18.0-38.2 $\mu \mathrm{g}$, respectively. The amount of m-HQ17(1) leveled off after $8 \mathrm{~h}$ of treatment. The amount of c-HQ17(1) was increased from 4 to $12 \mathrm{~h}$, but it was decreased when the treatment was longer than $24 \mathrm{~h}$, indicating that there may be some intracellular HQ17(1) degradation on long-time incubation. For each time point, the amounts of m-HQ17(1) were slightly more than c-HQ17(1). If the cytosol/membrane volume ratio (CMVR) is considered, it
(A)

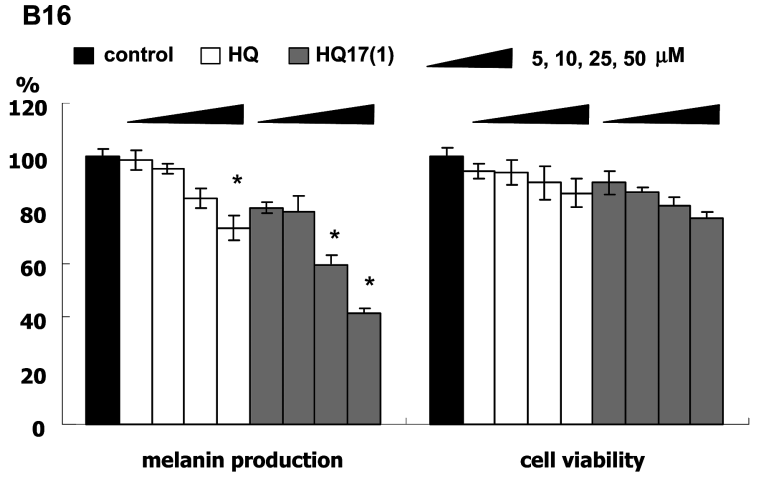

(B) A2058

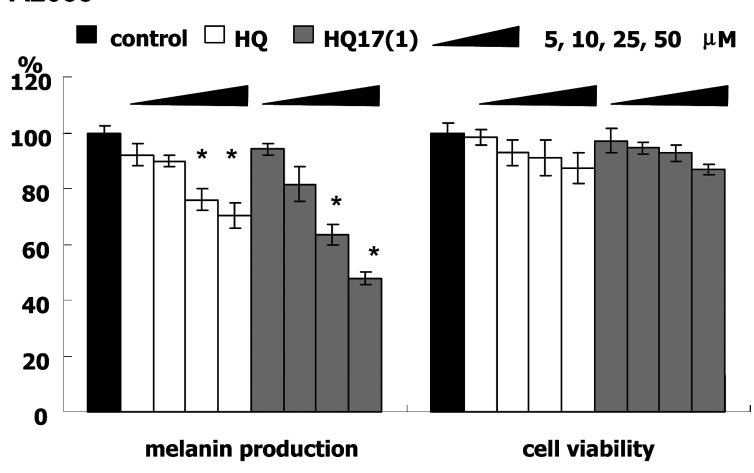

(C)

Melanocyte

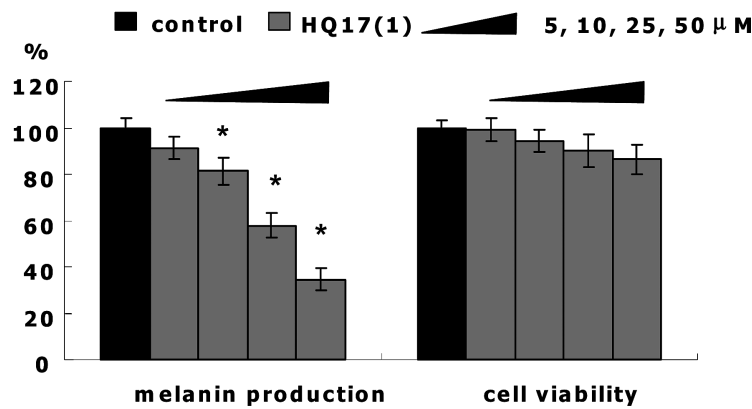

Figure 3. Inhibition of melanin production in mammalian cells by HQ17(1). The cells were stimulated with $\alpha-\mathrm{MSH}$ and cultured for $72 \mathrm{~h}$ in the presence of HQ17(1) or HQ. The level of melanin in the culture medium was measured by absorbance at $400 \mathrm{~nm}$, and cell viability was measured by ACP assay. The data presented are the averages derived from triplicate experiments. The asterisk $\left(^{*}\right)$ indicates $p<0.05$.

is conceivable that the concentration of HQ17(1) in membrane is much higher than in cytoplasm. As an example, CMVR for a cell has been measured in neuron cells, and a value of 83 was indicated (25). The concentration of HQ17(1) in the membrane could be several ten-fold higher than that in the cytoplasm. These results suggest that $\mathrm{HQ17}(1)$ is favorably associated with membrane; thus, the m-HQ17(1) reached a steady level at $8 \mathrm{~h}$, and the level was maintained later. As mammalian tyrosinase is a trans-membrane protein (5), the steady concentration of m-HQ17(1) after $8 \mathrm{~h}$ of exposure may explain why the intermittent treatment and $72 \mathrm{~h}$ continuous treatment of HQ17(1) caused the same level of inhibition.

HQ17(1) Induced Less Cellular ROS than HQ. As indicated by previous studies, HQ induced cellular ROS, which can lead to inflammatory responses and cellular oxidative damage $(10,11)$. The induction of ROS by HQ17(1) or HQ was measured by DCFDA staining and flow cytometry as shown in Figure 5A. The cells treated with $100 \mu \mathrm{M} \mathrm{H}_{2} \mathrm{O}_{2}$ served as a positive control, and the high-ROS cells were those with 
(A)

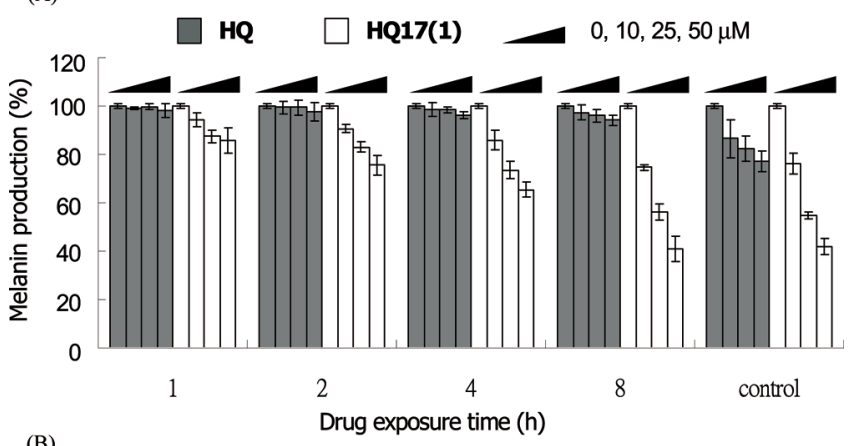

(B)

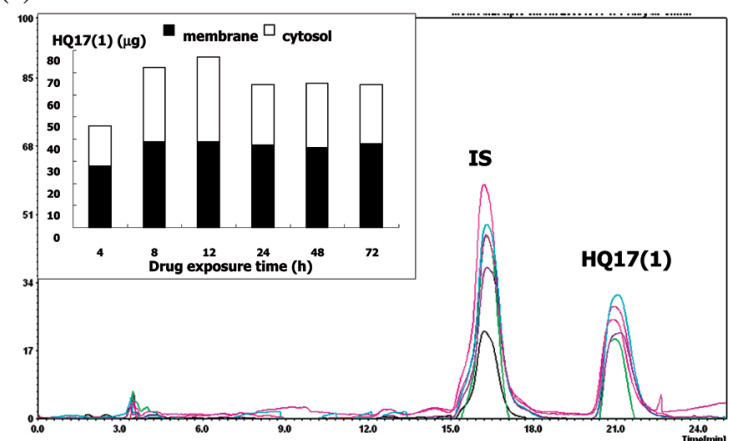

Figure 4. (A) Inhibition of melanin production. B16 cells were treated with $\mathrm{HQ17}(1)$ or $\mathrm{HQ}$ for the indicated time, and the cells were then cultured in a medium without the drug. The cells in the control group were treated with the drug for $72 \mathrm{~h}$. At the end, melanin levels in the culture media were measured. Averages of data from triplicate experiments are shown. (B) Cellular distribution of HQ17(1). The cells were treated with $82.6 \mu \mathrm{g}$ of $\mathrm{HQ17}(1)$ [ $6 \mathrm{~mL}$ of medium containing $40 \mu \mathrm{M} \mathrm{HQ17(1)]} \mathrm{for} \mathrm{4-72} \mathrm{h}$. The cells were collected, the membrane and cytosol fractions were prepared, and $34.4 \mu \mathrm{g}$ of internal standard (IS) was added for quantification as described under Materials and Methods. Ethanol extractions of both fractions were subjected to HPLC analysis. The HPLC chromatogram (monitored at $A_{280 \mathrm{~nm}}$ ) shows the recovered HQ17(1) from membrane fractions of cells treated with HQ17(1) for $4,8,12,24,48$, and $72 \mathrm{~h}$. The HPLC result of the cytosol fraction is in Supporting Information Figure 1. (Inset) Amount of recovered HQ17(1) in the membrane fraction and the cytosol fraction at the indicated time based on calculation of peak areas relative to IS.

fluorescence intensity higher the arrow. The results shown in Figure 5A were analyzed by software, and the percentages of the high-ROS cell populations induced by HQ17(1) and HQ were plotted and are shown in Figure 5B. Treatment of B16 cells with $40 \mu \mathrm{M}$ HQ17(1) (the $\mathrm{EC}_{50}$ for melanin production inhibition) induced only a $7 \%$ high-ROS cell population. HQ at the same concentration induced a $37 \%$ high-ROS cell population. When the concentration was raised to $60 \mu \mathrm{M}, 19$ and $48 \%$ high-ROS cell populations were induced by HQ17(1) and HQ, respectively. These results indicate that HQ17(1) elicited much less cellular ROS than HQ and could thus be a better antimelanogenesis agent.

In this study, HQ17(1) from the sap of $R$. succedanea was found to inhibit the activity of tyrosinase in vitro and melanogenesis in mammalian melanocytes with better efficiency than HQ. Furthermore, it elicited only $7 \%$ high-ROS cell population at the $\mathrm{EC}_{50}$ for melanin production inhibition, implying that inhibition of melanin production by HQ17(1) was not the result of cell damage by ROS. Contrarily, HQ at $60 \mu \mathrm{M}$ (a concentration much lower than $124 \mu \mathrm{M}$, the $\mathrm{EC}_{50}$ for melanin production inhibition) caused about $50 \%$ of the cells in a high-ROS state, suggesting that the decrease in melanin production by HQ might be the result of cell damage caused by ROS.
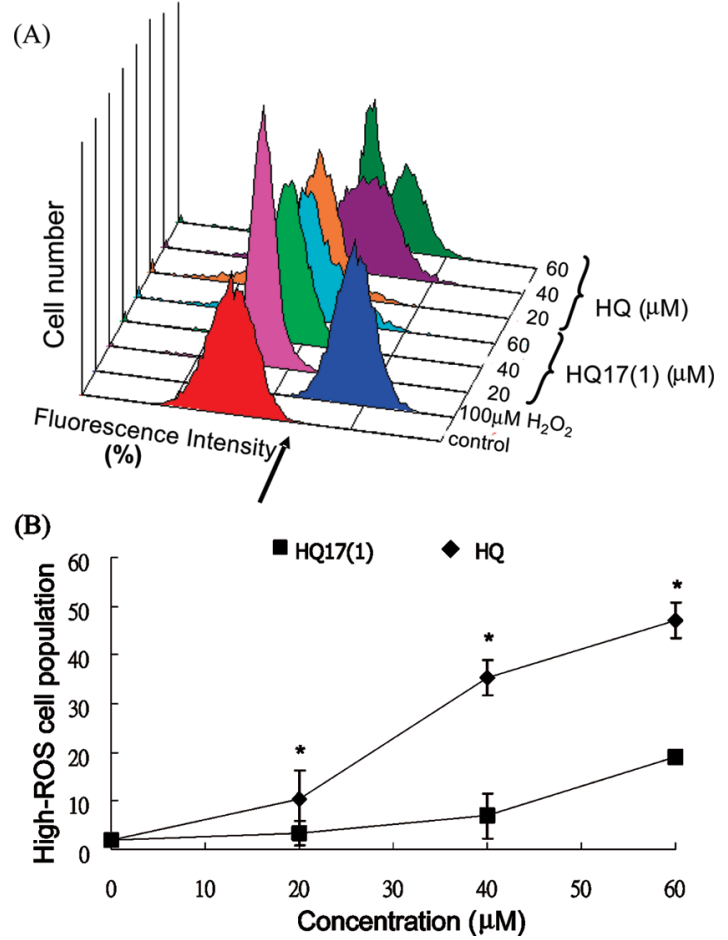

Figure 5. Reactive oxygen species (ROS) production induced by HQ17(1) and $H Q$. B16 cells were cultured in the presence of the test compounds or without a compound (control group) for $8 \mathrm{~h}$. The cells were then incubated with DCFDA and analyzed by flow cytometry. Treatment of the cells with $\mathrm{H}_{2} \mathrm{O}_{2}(100 \mu \mathrm{M})$ served as a positive control. (A) Flow cytometry data. The basal cellular ROS level is shown as the control group. The cellular ROS converted DCFDA to fluorescent DCF. High-ROS cells were those with fluorescence higher than the level indicated by the arrow. (B) The percentage of the high-ROS cell populations shown in $(\mathbf{A})$ was calculated and plotted. All experiments were triplicated and presented as mean \pm SD The asterisk $\left(^{*}\right)$ indicates $p<0.05$.

In previous studies, HQ17(1) was found to be toxic for cancer cell lines of brain, breast, colon, lung, liver, and prostate origin. The $\mathrm{EC}_{50}$ values for these cancer cell lines are at concentrations less than or near $10 \mu \mathrm{M}(15,20)$. Our study indicated that cells of skin origin seem to be more resistant to HQ17(1). The results shown above demonstrate that HQ17(1) was much less toxic in melanoma cells and normal melanocytes. Similarly, HQ17(1) was less toxic for human skin fibroblasts (WS-1 cells) or human keratinocytes. When these skin cells were treated with $50 \mu \mathrm{M}$ HQ17(1), the cell viability was kept around 90\%. Among the three alkylhydroquinones isolated from Rhus sap, HQ17(3) is the most cytotoxic for most of the test cell lines. We have demonstrated that in HL-60 leukemia cells, the cytotoxicity mechanism of HQ17(3) involves topoisomerase II poisoning (19). An in vitro assay showed that HQ17(1) and HQ17(3) at a concentration of $40 \mu \mathrm{M}$ caused 19 and $70 \%$ inhibition on topoisomerase II activity, respectively. HQ17(1) apparently is not as good a topoisomerase II inhibitor as HQ17(3). In addition to being a weak topoisomerase II inhibitor, the low cytotoxicity of HQ17(1) may also due to the fact that HQ17(1) is more hydrophobic than HQ17(3) and tends to be retained in the cell membrane, thus readily inhibiting the function of membrane protein, such as tyrosinase, and exerting less effect on nonmembrane proteins. The hydrophobicity of HQ17(1) could also account for its efficacy in antimelanosis achieved by intermittent treatment. In addition to facilitating retention of the compound in the membrane compartment, the inductive and mesomeric effects of alkyl substituents on the aromatic ring system may 
contribute to the impediment of oxidation of the hydroquinone ring, thereby generating fewer ROS.

In conclusion, we have demonstrated that HQ17(1) is a more effective and less harmful tyrosinase inhibitor than HQ. In addition to the conventional preservative or cosmetic applications, such a tyrosinase inhibitor might be pharmaceutically useful for the treatment of Parkinson's disease. Recently, many researchers have indicated that tyrosinase activity contributes to the formation of neuromelanin, which exacerbates dopamine neurotoxicity and is associated with Parkinson's disease $(26,27)$. The use of botanical tyrosinase inhibitors in medicine would increase the additive value of agricultural products. However, HQ17(1) must, despite its undisputed advantages over HQ, be evaluated carefully in the same manner as HQ, and its safety must be proven before it can be envisaged to bring such a compound into the food chain.

Supporting Information Available: HPLC results. This material is available free of charge via the Internet at http:// pubs.acs.org.

\section{LITERATURE CITED}

(1) Mayer, A. M. Polyphenol oxidases in plants and fungi: going places? A review. Phytochemistry 2006, 67, 2318-2331.

(2) Solomon, E. I.; Sundaram, U. M.; Machonkin, T. E. Multicopper oxidases and oxygenases. Chem. Rev. 1996, 96, 2563-2606.

(3) Seo, S. Y.; Sharma, V. K.; Sharma, N. Mushroom tyrosinase: recent prospects. J. Agric. Food Chem. 2003, 51, 2837-2853.

(4) Friedman, M. Food browning and its prevention: an overview. $J$. Agric. Food Chem. 1996, 44, 631-653.

(5) Lin, J. Y.; Fisher, D. E. Melanocyte biology and skin pigmentation. Nature 2007, 445, 43-50.

(6) Gilchrest, B. A.; Park, H. Y.; Eller, M. S.; Yaar, M. Mechanisms of ultraviolet light-induced pigmentation. Photochem. Photobiol. 1996, 63, 1-10.

(7) Parvez, S.; Kang, M.; Chung, H. S.; Bae, H. Naturally occurring tyrosinase inhibitors: mechanism and applications in skin health, cosmetics and agriculture industries. Phytother. Res. 2007, 21, $805-816$

(8) Kim, Y. J.; Uyama, H. Tyrosinase inhibitors from natural and synthetic sources: structure, inhibition mechanism and perspective for the future. Cell. Mol. Life Sci. 2005, 62, 1707-1723.

(9) Nordlund, J. J.; Grimes, P. E.; Ortonne, J. P. The safety of hydroquinone. J. Eur. Acad. Dermatol. Venereol. 2006, 20, 781787.

(10) Luo, L.; Jiang, L.; Geng, C.; Cao, J.; Zhong, L. Hydroquinoneinduced genotoxicity and oxidative DNA damage in HepG2 cells. Chem.-Biol. Interacttions 2008, 173, 1-8.

(11) Joseph, P.; Klein-Szanto, A. J.; Jaiswal, A. K. Hydroquinone cause specific mutations and lead to cellular transformation and in vivo tumorigenesis. Br. J. Cancer 1998, 78, 213-320.

(12) Chakraborty, A. K.; Funasaka, Y.; Komoto, M.; Ichihashi, M. Effect of arbutin on melanogenesis proteins in human melanocytes. Pigment Cell Res. 1998, 11, 206-212.

(13) Nihei, K.; Kubo, I. Identification of oxidation product of arbutin in mushroom tyrosinase assay system. Bioorg. Med. Chem. Lett. 2003, 13, 2409-2412.
(14) Curto, E. V.; Kwong, C.; Hermersdorfer, H.; Glatt, H.; Santis, C.; Virador, V; Hearing, V. J. , Jr.; Dooley, T. P. Inhibitors of mammalian melanocyte tyrosinase: in vitro comparisons of alkyl esters of gentisic acid with other putative inhibitors. Biochem. Pharmacol. 1999, 57, 663-672.

(15) Wu, P. L.; Lin, S. B.; Huang, C. P.; Chiou, R. Y.-Y. Antioxidative and cytotoxic compounds extracted from the sap of Rhus succedanea. J. Nat. Prod. 2002, 65, 1719-1721.

(16) Oshima, R.; Yamauchi, Y.; Watanabe, C.; Kumanotani, J. J. Enzymatic oxidative coupling of urushiol in sap of the Lac tree Rhus vernicifera. J. Org. Chem. 1985, 50, 2613-2621.

(17) Kumanotani, J. Enzyme catalyzed durable and authentic oriental lacquer: a natural microgel-printable coating by polysaccharideglycoprotein-phenolic lipid complexes. Prog. Org. Coatings 1998, 34, 135-146.

(18) Yan, X.; Zou, J.; Xie, G. Traditional Chinese Medicines: Molecular Structure, Natural Sources, and Applications; Ashgate Publishing: Farnham, U.K., 1999; pp 722-730.

(19) Huang, C. P.; Fang, W. H.; Lin, L. I.; Chiou, R. Y.; Kan, L. S.; Chi, N. H.; Chen, Y. R.; Lin, T. Y.; Lin, S. B. Anticancer activity of botanical alkyl hydroquinones attributed to topoisomerase II poisoning. Toxicol. Appl. Pharmacol. 2008, 227, 331-338.

(20) David, J. M.; Chavez, J. P.; Chai, H. B.; Pezzuto, J. M.; Cordell, G. A. Two new cytotoxic compounds from Tapirira guianensis. J. Nat. Prod. 1998, 61, 287-289.

(21) Li, C. H.; Chen, P. Y.; Chang, U. M.; Kan, L. S.; Fang, W. H.; Tsai, K. S.; Lin, S. B. Ganoderic acid X, a lanostanoid triterpene, inhibits topoisomerases and induces apoptosis in cancer cells. Life Sci. 2005, 77, 256-265.

(22) Siegrist, W.; Eberle, A. N. In situ melanin assay for MSH using mouse B16 melanoma cells in culture. Anal. Biochem. 1986, 159, 191-197.

(23) Lehner, I.; Niehof, M.; Borlak, J. An optimized method for the isolation and identification of membrane proteins. Electrophoresis 2003, 24, 1795-1808.

(24) Murrant, C. L.; Reid, M. B. Detection of reactive oxygen and reactive nitrogen species in skeletal muscle. Microsc. Res. Technol. 2001, 55, 236-248.

(25) Winks, J. S.; Hughes, S.; Filippov, A. K.; Tatulian, L.; Abogadie, F. C.; Brown, D. A.; Marsh, S. J. Relationship between membrane phosphatidylinositol-4,5-bisphosphate and receptor-mediated inhibition of native neuronal M channels. J. Neurosci. 2005, 25, 3400-3413.

(26) Greggio, E.; Bergantino, E.; Carter, D.; Ahmad, R.; Costin, G. E.; Hearing, V. J.; Clarimon, J.; Singleton, A.; Eerola, J.; Hellström, O.; Tienari, P. J.; Miller, D. W.; Beilina, A.; Bubacco, L.; Cookson, M. R. Tyrosinase exacerbates dopamine toxicity but is not genetically associated with Parkinson's disease. J. Neurochem. 2005, 93, 246-256.

(27) Tessari, I.; Bisaglia, M.; Valle, F.; Samorì, B.; Bergantino, E.; Mammi, S.; Bubacco, L. The reaction of $\alpha$-synuclein with tyrosinase: possible implications for Parkinson's disease. J. Biol. Chem. 2008, 283, 16808-16817.

Received for review August 25, 2008. Revised manuscript received November 12, 2008. Accepted November 13, 2008. This work is supported by National Sciences Council, Taiwan, Republic of China, Grants NSC-96-2320-B-002-014 and NSC 97-2320-B-002-024.

JF802617A 